\title{
Findings of Paediatric Upper Gastrointestinal Endoscopy at a Tertiary Care Centre
}

\author{
Thapa $\mathrm{SB}^{1}$, Sharma $\mathrm{AK}^{2}$
}

\begin{abstract}
Introduction: Endoscopy is an important diagnostic tool for gastrointestinal disorders in children. Practitioners still debate the need and utility of endoscopy in children and this important evaluation is potentially underutilized. There is a paucity of paediatric endoscopy data in Nepal. This report describes an initial three-year experience on profile of upper gastrointestinal endoscopy at Tribhuvan University Teaching Hospital (TUTH). Material and Methods: This retrospective study was conducted by reviewing hospital records for children undergoing endoscopy for various indications at TUTH during November 2011 to October 2014 (3 years). Results: We performed 362 endoscopies during this period. Mean age of patients was 9.49 years (range 2 months to 18 years) and 199 (54.9\%) patients were under 10 years of age. Common indications were upper gastrointestinal bleeding $(27.6 \%)$, recurrent abdominal pain $(26.2 \%)$, acute abdominal pain $(24.6 \%)$, recurrent vomiting $(5.2 \%)$, and caustic ingestion (3.6\%). An abnormality was detected in 159 $(42.2 \%)$ patients. Varices (16.6\%), gastritis/duodenitis $(14.9 \%)$, ulcer $(3.3 \%)$, oesophagitis $(1.9 \%)$ were common diagnoses. Etiology of upper gastrointestinal bleed was identified in $65 \%$ of patients. Majority of patients with recurrent abdominal pain had negative results $(80 \%)$. Failure to thrive constituted a very small proportion of children $(0.2 \%)$ evaluated. All children received sedation/ analgesia and tolerated the procedure well. Conclusion: Paediatric upper gastrointestinal endoscopy can be safely performed across wide age range with proper sedation/ analgesia. Endoscopic diagnosis may improve management and children requiring such evaluation should be timely referred. Paediatricians should be encouraged to refer patients with growth failure early to ensure proper management.
\end{abstract}

Key words: Paediatrics, Upper gastrointestinal endoscopy, Nepal

\section{Introduction}

Ever since Hirschowitz introduced fiberoptic endoscopes in the

1970s, understanding of the paediatric gastrointestinal disorders has become more and more broad ${ }^{1,2}$. Upper gastrointestinal endoscopy (UGIE) has served as a basic tool for diagnosis and therapy in paediatric gastrointestinal disorders in much of the developed world right after this discovery. It has also fostered development of
'Dr. Surya Bahadur Thapa, Lecturer. ${ }^{2}$ Dr. Arun Kumar Sharma, Associate Professor. Both from the Department of Paediatrics, Tribhuvan University Teaching Hospital, Kathmandu, Nepal

\author{
Address for correspondence: \\ Dr. Arun Kumar Sharma \\ Associate Professor, Department of Paediatrics, \\ Tribhuvan University Teaching Hospital, \\ Kathmandu, Nepal \\ E-mail: docarunsharma@hotmail.com \\ Tel: +9779851007462
}

\section{How to cite}

Thapa SB, Sharma AK. Findings of Paediatric Upper Gastrointestinal Endoscopy at a Tertiary Care Centre. J Nepal Paediatr Soc 2015;35(2):123-128.

doi: http://dx.doi.org/10.3126/jnps.v35i2.13595

This work is licensed under a Creative Commons Attribution 3.0 License.

\section{(c) (1)}

paediatric gastroenterology as an important discipline in the medical diversity ${ }^{1,2,3,4,5}$. Endoscopic techniques have become the most cost-effective and efficient methods in many common paediatric gastrointestinal disorders with technological advance in this field.

In the developing world however, use of gastrointestinal endoscope in paediatrics is still in infancy. Lack of awareness of its application, limited paediatric friendly endoscopy suites/endoscopes and lack of adequately trained physicians who can safely perform the procedure are the greatest hurdles, ${ }^{6,7}$ Paediatric gastroenterology services have just started 
to be recognized as important subspecialty in Nepal and we are still far from utilization of technical advance with this procedure. Tribhuvan University Teaching Hospital (TUTH) serves as a referral hospital and has recently established a separate paediatric endoscopy suite with child friendly scope. It is one of very limited paediatric service available in the country. Majority of endoscopies performed in this centre are actually referrals from different medical centres across the country. Referrals to this service however are limited and the service is still underutilized.

We conducted this study with the objective of disseminating the information on common indications and findings of UGIE among all paediatricians of the country.

\section{Material and Methods}

This is a retrospective study conducted in Department of Paediatrics at TUTH. TUTH is a referral hospital and patients arrive to this hospital from all over the country. It has a separate paediatric endoscopic suite with child friendly paediatric video gastro-duodenoscope. We performed upper gastrointestinal (UGI) endoscopy for all patients referred by paediatricians. Informed consent was obtained from parents/patients for the procedure after careful explanation of procedure details and potential complications. All children underwent the procedure under ketamine and midazolam sedation/anaesthesia in accordance to their comfort level and cooperation for the procedure. Lignocaine gargle was applied for some adolescents to reduce the dose of intravenous anaesthetics. A paediatrician monitored the child during the procedure without any other responsibilities while the endoscopist performed the procedure. Trained paediatricians performed all endoscopies. Endoscopy findings were recorded, biopsies taken for histopathological examination and serological tests were sent wherever necessary. After the procedure, patients stayed in observation until the reversal of effect of anaesthesia and the child accepted oral fluids without problems. We recorded all information collected electronically and in the patient file.

We conducted this retrospective study by reviewing the hospital and endoscopy room records and extracting the data. We reviewed all the patients, who underwent upper gastrointestinal (UGI) endoscopy from October 2011 to October 2014 over a period of three years. The data was analyzed using SPSS (Version 20) statistical program. We calculated the frequencies of various indications, endoscopic findings, and histopathological findings for UGI endoscopy.

\section{Results}

During the study period, 362 patients underwent UGI endoscopy. Mean age of patients undergoing the procedure was 9.49 years (Range: 2 months to 18 years) with median of 10 years (standard deviation $\sigma=3.68$ ). Majority of them were male (Fig 1) and children under the age of 10 years constituted $55 \%$ of patients undergoing UGI endoscopy. (Fig 2)

Table 1 summarizes the various indications for UGI endoscopy. Major indications in our service were UGI bleed, recurrent abdominal pain, acute abdominal pain and recurrent vomiting.

Table 2 describes the endoscopic findings in all patients. Normal findings were observed in majority of patients (57.7\%). Varices (16.6\%), Gastritis/Duodenitis (14.9\%), Ulcer disease (3.3\%) and oesophagitis (1.9\%) were among the most commonly identified abnormalities. Upper gastrointestinal obstructions in the form of strictures were also identified during UGI endoscopy. Congenital obstructions were all gastric outlet obstructions without any mucosal endoscopic findings. Acquired strictures were all post caustic ingestion strictures and ulcerative/inflammatory narrowing of gastric outlet.

Table 1: Indications for endoscopy in study population

\begin{tabular}{|l|c|}
\hline Primary Indication/symptom & Number \%) \\
\hline UGI bleed & $100(27.6)$ \\
\hline Recurrent abdominal pain & $95(26.2)$ \\
\hline Acute abdominal pain & $89(24.6)$ \\
\hline Recurrent vomiting & $19(5.2)$ \\
\hline Caustic ingestion & $13(3.6)$ \\
\hline Unexplained splenomegaly & $12(3.3)$ \\
\hline Post splenectomy status & $8(2.2)$ \\
\hline Acute vomiting & $6(1.7)$ \\
\hline Gastric outlet obstruction & $5(1.4)$ \\
\hline Dysphagia & $5(1.4)$ \\
\hline Lower GI bleed & $5(1.4)$ \\
\hline Foreign body & $2(0.6)$ \\
\hline Failure to thrive & $2(0.6)$ \\
\hline Screening for familial polyposis & $1(0.3)$ \\
\hline Total & $362(100)$ \\
\hline
\end{tabular}


Table 2: Findings of UGI endoscopy in study population

\begin{tabular}{|l|c|}
\hline \multicolumn{1}{|c|}{ Endoscopic findings } & Number (\%) \\
\hline Normal & $209(57.7)$ \\
\hline Varices & $60(16.6)$ \\
\hline Gastritis/ Duodenitis & $54(14.9)$ \\
\hline Ulcer & $12(3.3)$ \\
\hline Oesophagitis & $7(1.9)$ \\
\hline Acquired stricture & $6(1.7)$ \\
\hline Congenital obstructions & $4(1.1)$ \\
\hline Hiatus hernia & $4(1.1)$ \\
\hline Mucosal findings of celiac disease & $2(0.6)$ \\
\hline Foreign body & $2(0.6)$ \\
\hline Polyp & $1(0.3)$ \\
\hline Extrinsic esophageal compression & $1(0.3)$ \\
\hline
\end{tabular}

We also analyzed the endoscopic findings of patients undergoing the procedure for specific indications. UGI bleeding was the most common indication in our service. Varying severity of UGI bleeding was the primary indication for endoscopy in 100 patients but 35\% of them had a negative endoscopy. Varices (50\%) and gastritis/ duodenitis $(15 \%)$ in various forms were the most common endoscopically recognized abnormalities for bleeding. Colonoscopy was not performed in any patient. All patients with obscure UGI bleed were inactive (i.e. no evidence of ongoing bleed).

Abdominal pain either acute or recurrent, was other most common reasons for endoscopy referrals. Majority of patients in these categories had normal findings. Among 95 children with recurrent abdominal pain, 76 (80\%) had normal endoscopic findings. Gastritis/duodenitis 10 (10.5\%), duodenal and antral ulcers 7 (7.4\%) were some of the lesions identified in children with recurrent abdominal pain. Similarly,

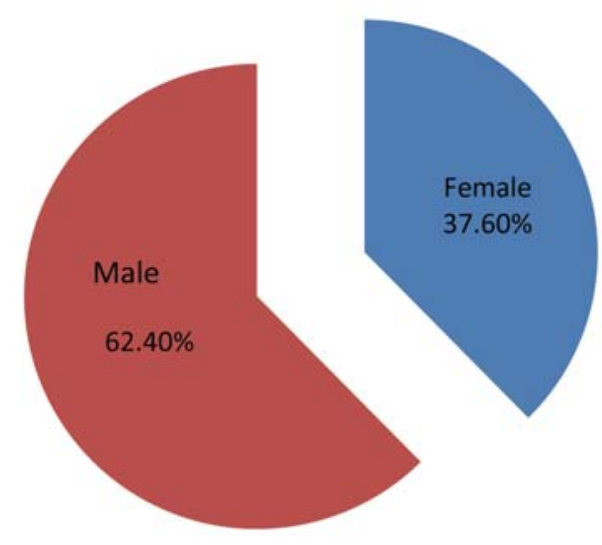

Fig 1: Showing gender distribution of children who underwent endoscopy among 89 children with acute abdominal pain, normal endoscopic result was obtained in 62 (69.7\%) patients. Gastritis /duodenitis 17 (19.1\%), ulcers 4 (4.5\%), oesophagitis $2(2.2 \%)$ were the most common endoscopically determined aetiologies for acute abdominal pain.

Recurrent vomiting was the principal indication of UGI endoscopy in 19 children. Majority of these patients 13 (68.4\%) also had normal findings; only 5 (26.3\%) patients had some positive endoscopic findings: 3 (15.8\%) patients had gastritis/ duodenitis, 1 (5.3\%) had ulcer and 1 (5.3\%) had oesophagitis.

Endoscopy was negative for all five patients who underwent UGI endoscopy for evaluation of lower GI bleed. Endoscopy revealed persistent varices for all patients who underwent evaluation following postsplenectomy and devascularization surgery for extrahepatic portal venous obstruction (EHPVO).

Failure to thrive is one of the most common reasons to perform paediatric endoscopy in children in order to obtain tissue samples for diagnosis of celiac disease. However, only a small proportion of patients were referred to our endoscopy service for this indication. Duodenal biopsies from each of these patients revealed histopathological findings consistent with celiac disease and corroborated with high serological titers for tissue transglutaminase (tTG) antibodies confirming diagnosis of celiac disease.

Patients tolerated sedation/ anesthesia with ketamine and midazolam administered to their level of comfort. Only two patients developed transient deterioration in oxygen saturation that improved on supplemental oxygen.

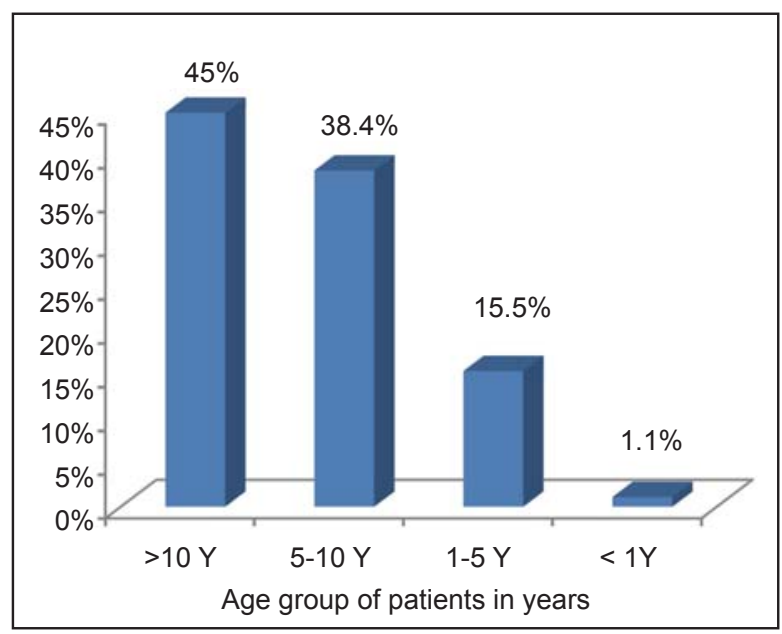

Fig 2: Showing proportion of children who underwent endoscopy in different age groups 


\section{Discussion}

Upper gastrointestinal endoscopy is an important diagnostic and therapeutic tool for gastrointestinal disorders in children ${ }^{8}$. There is a rising trend of diagnostic and therapeutic utility of UGI endoscopy in children in parallel with increasing spectrum of its indications in the western world ${ }^{9}$. However, this diagnostic and therapeutic modality is underutilized in majority of the underdeveloped world due to lack of manpower, equipment and difficulties of invasive procedure in children. The scenario is rapidly changing in many areas of the developing world although Nepal has lagged behind in this development. We have very limited adult endoscopy service in the country and paediatric services were almost nonexistent until the recent past ${ }^{10}$. Many paediatricians in Nepal therefore are not aware of the availability of services and many needy patients get treatment on presumptive grounds alone in absence of endoscopic diagnosis. Tribhuvan University Teaching Hospital (TUTH) is one of the major referral centres in the country and has recently started this important service. This study intends to present the experience of the paediatric endoscopy suite of TUTH to make paediatricians of the country aware on availability of service in the country and share our experience on common indications and findings of paediatric endoscopy in Nepalese children.

Indications for UGI endoscopy from developing and developed countries are reportedly different. Growth failure is the most common indication for UGI endoscopy in children in the west; in contrast, literature from most of the developing countries report abdominal pain as the most common indication for UGI endoscopy ${ }^{11}$. Abdominal pain, acute or recurrent accounted for $50.8 \%$ of all endoscopies performed in our patients. Similar figures are reported in other developing countries ${ }^{11,12}$. Studies from specialized gastroenterology centre or developed world however report much lower proportions of children undergoing endoscopy primarily for abdominal pain ${ }^{6}$.

In our study, $26.2 \%$ children underwent the procedure for recurrent abdominal pain and $24.6 \%$ were scoped for acute abdominal pain. Yield of endoscopic diagnosis in children with recurrent abdominal pain is consistently low in published literature although results are better with acute abdominal pain ${ }^{13,14}$. In our series, $80 \%$ patients with recurrent abdominal pain had negative UGI endoscopy. A systematic review in this subject showed a low diagnostic yield of UGIE in children with recurrent abdominal pain and concluded that utility of the procedure for change in treatment, quality of life, improvement of abdominal pain, and cost-effectiveness is unknown ${ }^{14}$. Although diagnostic yield has varied across studies, UGIE is still valuable for specific diagnosis and has therapeutic implications in many children with chronic abdominal pain ${ }^{15}$.

The commonest indication for patients undergoing UGI endoscopy in our study was upper GI bleed (27.6\%) followed by recurrent abdominal pain (26.2\%). Endoscopy remains the principal method used to identify the source of bleeding and to perform therapeutic procedures if necessary ${ }^{16}$. Oesophageal varices (50\%) were the most commonly identified lesions leading to UGI bleed among patients who underwent endoscopy for the UGI bleed. High diagnostic yield of varices has also been reported in other studies ${ }^{17,18}$ and probably represent the group of patients catered by the endoscopic service rather than the actual prevalence of varices responsible for UGI bleed ${ }^{19}$. Endoscopic services in this country are still in infancy and our endoscopy service was the first paediatric service to serve children with GI bleeding. Majority of patients with minor or self-limiting bleeds obviously were not advised endoscopy. In addition, high incidence of portal hypertension is known to exist in underdeveloped and poorer areas of the world ${ }^{20}$ and there is marked difference in aetiologies of upper GI bleeding in children in reports from the developed and developing countries ${ }^{17,19,21,22}$. However, $35 \%$ of patients undergoing endoscopy in our series did not show an evident bleeding. Giannakopoulos et al reported a poor diagnostic yield of endoscopy performed after an episode of non-variceal bleeding; an evident bleeding source was discovered in only $5 \%$ of such endoscopies ${ }^{23}$. A high rate of negative endoscopies has also been reported in other studies that looked at all aetiologies of GI bleed ${ }^{6,24,25}$.

Growth failure/ Failure to thrive is major indication for endoscopy in children to obtain tissue for histology of the duodenum as this is the most preferred and accepted diagnostic test for celiac disease ${ }^{26}$. Celiac disease has been identified as one of the most common aetiology for growth failure in young children ${ }^{27}$. A rising trend of celiac disease diagnosis has been reported in Indian studies ${ }^{28,29}$. Majority of Nepalese population has Indo-Aryan ancestry and closely resembling dietary practice. Prevalence of celiac disease in Nepal is therefore likely to match north Indian population due to identical genetic and dietary risk factors. However, celiac disease is reported in Nepalese children infrequently. This is reflected in number of patients referred for endoscopy in our series. Only $0.6 \%$ of patients in this series underwent endoscopy with primary indication 
of failure to thrive. The latest Nepal Demographic and Health Survey reported under five stunting and wasting rate of $41 \%$ and $11 \%$ respectively ${ }^{30}$. Majority of these children certainly have chronic malnutrition as the primary cause; however, a substantial number of these children may have hidden celiac disease. Celiac disease has long-term health implications and its association with many other chronic diseases are emerging ${ }^{31,32}$. Overt celiac disease is readily diagnosed and managed; however, there should be a high index of suspicion in children with growth failure without overt manifestations ${ }^{33}$. Successive national surveys have shown improvement in nutritional status of children in the country and paediatricians are more likely to identify and treat growth failure of organic causes rather than nutritional deficiencies in future. A high index of suspicion, performing serological tests and early referral to endoscopy services should improve growth and health status of many of these children with celiac disease.

Potential serious airway problems such as laryngospasm, partial airway obstruction, apnea, and stridor are reported during endoscopic procedure with use of ketamine and midazolam ${ }^{34}$. We performed the procedure safely without major problem in all patients under intravenous sedation/ anaesthesia with ketamine and midazolam. In all procedures, however, physician administering the sedation/ anaesthesia was only responsible for patient monitoring and airway management should such need arise. Such procedures are considered relatively safe if performed in accordance to the guidelines ${ }^{35}$.

\section{Conclusion}

Upper GI endoscopy can be performed as a safe procedure in paediatric patients without complications under adequate sedation with appropriate monitoring and use of child friendly endoscopes in a paediatric suite. Paediatricians should be aware of its diagnostic utility in their scope of practice and should use this service more frequently in diagnosis and management of common childhood ailments. Management of growth failure in Nepalese children should be revisited with emerging literature in Indian subcontinent. There is a need to expand this important service across the country.

Acknowledgements: We would like to acknowledge our sincere thanks to all the staff of endoscopy unit.

Funding: None

Conflict of Interest: None

Permission from IRB: Yes, We have received this permission

\section{References}

1. Haight $M$, Thomas D. Pediatric gastrointestinal endoscopy. The Gastroenterologist 1995;3(3):1816.

2. Sircus W. Milestones in the evolution of endoscopy: a short history. J $R$ Coll Physicians Edinb 2002;33(2):124-34.

3. Graham D, Klish W, Ferry G, Sabel J. Value of fiberoptic gastrointestinal endoscopy in infants and children. South Med J 1978;71(5):558-60.

4. Papp JP. Endoscopic experience in 100 consecutive cases with the olympus GIF endoscope. Am J Gastroenterol 1973;60(5):466.

5. Franciosi JP, Fiorino K, Ruchelli E, Shults J, Spergel J, Liacouras CA, et al. Changing Indications for Upper Endoscopy in Children over a 20 Year Period. J Pediatr Gastroenterol Nutr 2010;51(4):443.

6. Khan MR, Ahmed S, Ali SR, Maheshwari PK, Jamal MS. Spectrum of upper GI endoscopy in pediatric population at a tertiary care centre in Pakistan. Open J of Pediatrics 2014;4(3): 180-184

7. Mandeville KL, Krabshuis J, Ladep NG, Mulder CJ, Quigley EM, Khan SA. Gastroenterology in developing countries: issues and advances. World J Gastroenterol 2009;15(23):2839.

8. Gleason WA, Tedesco FJ, Keating JP, Goldstein PD. Fiberoptic gastrointestinal endoscopy in infants and children. J Pediatr 1974;85(6):810-3.

9. Gilger MA. Gastroenterologic endoscopy in children: past, present, and future. Curr Opin Pediatr 2001;13(5):429-34.

10. Joshi MR, Sharma SK, Baral MR. Upper GI endoscopy in children- in an adult suite. Kathmandu Univ Med J 2005; 3(2): 111-4

11. Memon IA, Lal M, Tariq S, Chand S. Upper Gastrointestinal Endoscopic Experience in Children. Medical Channel 2011;17(4): 30-33

12. Karim B. Upper gastrointestinal endoscopy in children-an experience at a paediatric gastroenterology unit. Mymensingh Med J 2003;12(2):124-7.

13. Dhroove G, Chogle A, Saps M. A million-dollar work-up for abdominal pain: is it worth it? J Pediatr Gastroenterol Nutr 2010;51(5):579-83.

14. Thakkar K, Gilger MA, Shulman RJ, El Serag HB. EGD in children with abdominal pain: a systematic review. Am J Gastroenterol 2007;102(3):654-61. 
15. Thakkar K, Chen L, Tessier ME, Gilger MA. Outcomes of children after esophagogastroduodenoscopy for chronic abdominal pain. Clin Gastroenterol Hepatol 2014;12(6):963-9.

16. Gershman G, Thomson M. Practical pediatric gastrointestinal endoscopy: $2^{\text {nd }}$ edition. John Wiley \& Sons; Hoboken, New Jersey 2012.

17. Yachha S, Khanduri A, Sharma B, Kumar M. Gastrointestinal bleeding in children. J Gastroenterol Hepatol 1996;11(10):903-7.

18. Mittal S, Kalra K, Aggarwal V. Diagnostic upper GI endoscopy for hemetemesis in children: experience from a pediatric gastroenterology centre in north India. Indian J Pediatr 1994;61(6):651-4.

19. Arora N, Ganguly S, Mathur P, Ahuja A, Patwari A. Upper gastrointestinal bleeding: etiology and management. Indian J Pediatr 2002;69(2):155-68.

20. Wani H, Ahmed B, Wani G, Masoodi I, Mustafa S. Extrahepatic portal venous obstruction (EHPVO). The Internet J Gastroenterol [Serial on the internet]. 2010;9(1). [8 pages]. Available from http://ispub.com/IJGE/9/1/11432

21. Cox K, Ament ME. Upper gastrointestinal bleeding in children and adolescents. Pediatrics 1979;63(3):408-13.

22. Kato S, Nakagawa H, Harada $Y$, Saito $Y$, Watanabe N, Abe J, et al. A clinical study of upper gastrointestinal endoscopy in Japanese children. Acta Paediatr Jpn 1991;33(2):36-42.

23. Giannakopoulos A, Logothetis A, Panayiotou J, Van-Vliet K, Orfanou I, Roma-Giannikou E. Poor endoscopic findings in children with non variceal upper gastrointestinal bleeding: is biopsy necessary? Hippokratia. 2010;14(4):261.

24. Hassoon AJ, Al Maeen A, Maltloub H. Upper gastrointestinal bleeding in children. J Fac Med Baghdad 2012;54(3): 223-227
25. Okello TR. Upper gastrointestinal endoscopic findings in adolescents at Lacor hospital, Uganda. Afr Health Sci 2006;6(1):39-42.

26. Guandalini S, Assiri A. Celiac disease: a review. JAMA Pediatr 2014;168(3):272-8.

27. Murray JA. The widening spectrum of celiac disease. Am J Clin Nutr 1999;69(3):354-65.

28. Sood A, Midha V, Sood N, Avasthi G, Sehgal A. Prevalence of celiac disease among school children in Punjab, North India. J Gastroenterol Hepatol 2006;21(10):1622-5.

29. Yachha SK. Celiac disease: India on the global map. J Gastroenterol Hepatol 2006;21(10):1511-3.

30. Demographic B. Health Survey 2011. Ministry of Health and Population, Government of Nepal Kathmandu[online] Available at: http:// www measuredhs com/pubs/pdf/FR257/FR257 [13April2012] pdf.

31. Catassi C, Bearzi I, Holmes GK. Association of celiac disease and intestinal lymphomas and other cancers. Gastroenterology 2005;128(4):S79-S86.

32. Green PH. The many faces of celiac disease: clinical presentation of celiac disease in the adult population. Gastroenterology 2005;128(4):S74-S8.

33. Catassi C, Fasano A. Celiac disease as a cause of growth retardation in childhood. Curr Opin Pediatr 2004;16(4):445-9.

34. Green SM, Klooster M, Harris T, Lynch EL, Rothrock SG. Ketamine sedation for pediatric gastroenterology procedures. J Pediatr Gastroenterol Nutr 2001;32(1):26-33.

35. Parker RI, Mahan RA, Giugliano D, Parker MM. Efficacy and safety of intravenous midazolam and ketamine as sedation for therapeutic and diagnostic procedures in children. Pediatrics 1997;99(3):427-31 